\title{
Simulation of Moving Granular-Bed Type Heat Exchanger ${ }^{\dagger}$
}

\author{
Tadayuki Minoura and Shun-ichi Mizukami \\ Mechanical Engineering Research Laboratory \\ Kobe Steel, Ltd.*
}

Hiroyuki Kohama

Chemical Industry Research Laboratory

Kobe Steel, Ltd.*

Takayoshi Asami

Engineering Division

Kobe Steel, Ltd.*

\begin{abstract}
A simulation of the moving granular-bed type heat exchanger, in which heat is transferred from the hot gas through granular materials and heat pipes to the cold gas, has been performed. A numerical simulation model was made by dividing each part of the heat exchanger into small elements, and heat balance was calculated using the finite difference method. The heat transfer coefficients and effective thermal conductivities of the granular bed in each part of the heat exchanger were estimated from a general theory, while the heat transfer coefficient between the granular bed and heat pipes was determined from the experiment.

The steady characteristics of the heat exchanger from the calculations were compared with the data obtained from the experiment. The calculation results coincided well with the experimental results. The method of modeling and simulation was confirmed to be accurately applicable to the estimation of the performance of the heat exchanger using granules as heat transferring media and heat pipes.
\end{abstract}

\section{Introduction}

Various types of heat exchangers consisting of heat pipes combined with a fluidized bed or a packed bed have been proposed. Since 1976, our company has been engaged in research and development on "A Moving Granular-Bed Type Heat Exchanger", which consists of corrosionresisting heat pipes combined with a moving granular-bed type dust collector, as one of the research contracts on a large-scale project entitled "Research and Development of Technical

* 1-chome, Wakinohama-cho, Chuo-ku, Kobe, 651 TEL. 078 (251) 1551

$\dagger$ This report was originally printed in J. Soc. Powder Tech., Japan, 20, 185-193 (1983) in Japanese, before being translated into English with the permission of the editorial committee of the Soc. Powder Tech., Japan.
Systems for Utilization of Waste Heat" sponsored by the Agency of Industrial Science and Technology of the Ministry of International Trade and Industry. In the moving granular-bed type heat exchanger, heat is transferred through the heat pipes with a moving bed as a heat carrier. In the present research, we performed a simulation, solving the fundamental equations obtained through modeling a moving granular-bed type heat exchanger by the finite difference method in order to evaluate the thermal efficiency of the heat exchanger. Furthermore, a comparison of the calculation results with the experimental ones showed that the constants used for the simulation, such as heat transfer coefficients, are appropriate in addition to the propriety of the proposed model. 


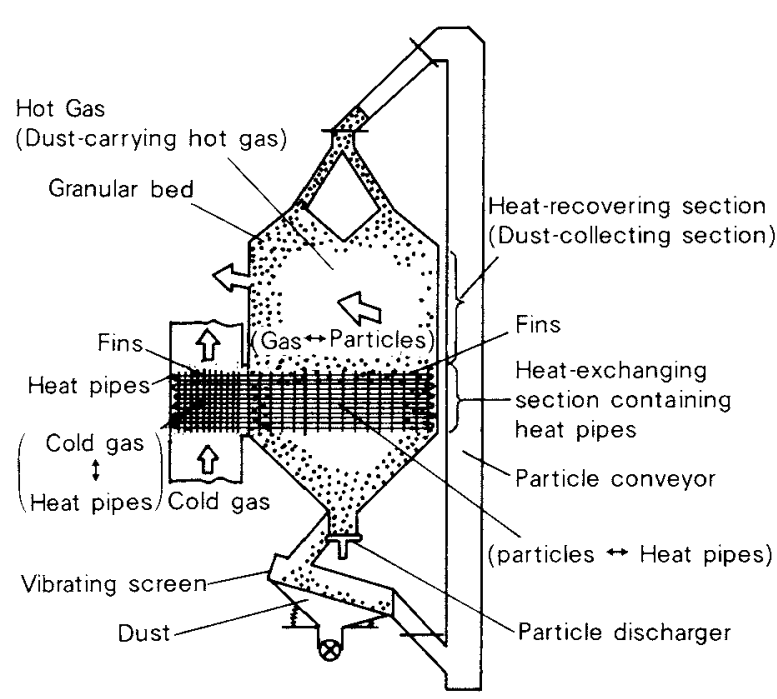

Fig. I Principale of moving granular-bed type heat exchanger

\section{Operational principle of moving granular- bed type heat exchanger}

The moving granular bed is, as shown in Fig. 1, so designed that the heat is exchanged between the hot and the cold gases through particles as a heat carrier. Namely at first, in the heat-recovering section, heat is transferred from the hot gas to the particles when it flows through the granular bed. The particles, having received heat from the hot gas, move downward due to gravitational force toward a constant discharger. In the heat-exchanging section containing the heat pipes, heat is transferred from the particles to the cold gas through heat pipes and is recovered for further utilization.

\section{Modeling}

\section{1 Fundamental equations}

In order to simplify the complicated heat transferring phenomena in the moving granularbed type heat exchanger, the following assumptions are made regarding the simulation model shown in Fig. 2.

(a) The particles move downward in the tower at a constant velocity in the $z$-direction.

(b) The hot gas flows through the granular bed cross-currently to the movement of the particles and diffusion of the hot gas in the $z$-direction is negligible.

(c) In the heat-recovering section, temperature distribution in the granular bed is two-dimen-

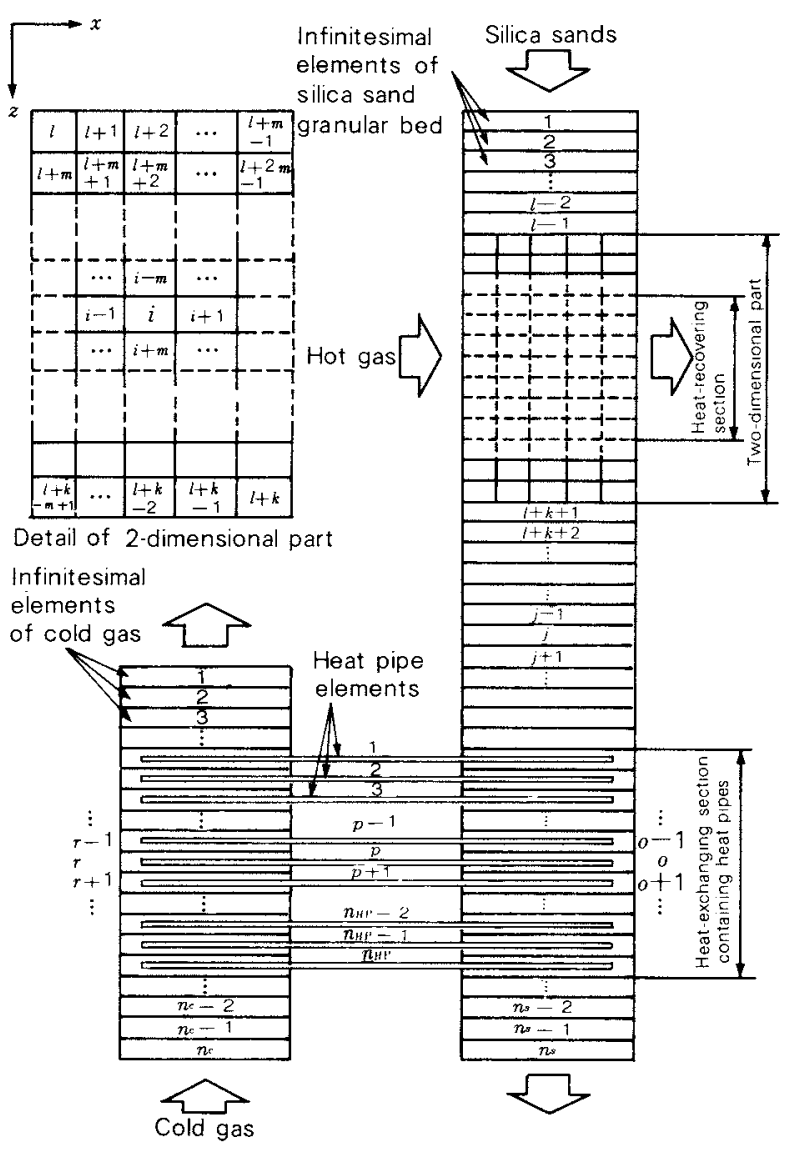

Fig. 2 A Model for simulation of the heat exchanger

sional, i.e. in the directions of particle movement and hot gas flow. In some parts of the upper and lower parts of the heat-recovering section, however, it can be regarded as onedimensional, neglecting the variation in the $x$ direction.

(d) In the heat-exchanging section of the heat pipes, the temperature of the granular bed in the $x$-direction is regarded to be uniform.

(e) The temperature inside the particles is uniform ${ }^{\text {th }}$.

(f) The heat pipes in the same row have the same temperature.

The heat resistance of these heat pipes them-

* The particles used in the present research (Silica Sands having a mean diameter of $1.75 \mathrm{~mm}$, thermal conductivity of $1.16 \mathrm{~W} / \mathrm{m}^{\circ} \mathrm{C}$, specific heat of $0.921 \mathrm{~kJ} / \mathrm{kg}^{\circ} \mathrm{C}$, density of $2620 \mathrm{~kg} / \mathrm{m}^{3}$ ) has a Biot number of 0.0035 , when it is set in a fluid flow under the assumption of spherical particles having uniform temperature and a heat transfer coefficient of $0.465 \mathrm{~W} / \mathrm{m}^{20} \mathrm{C}$ having the same order of that between the hot gas and the granular bed. In this way, the temperature distribution within the particles can be regarded as uniform, since the temperature difference between the surface and the center of the particles is always less than $1 \%$ of that between the particle center and the fluid ${ }^{1)}$. 
selves is negligibly small compared with that between the heat pipes and the particles as well as that between the heat pipes and the cold gas ${ }^{5}$.

(g) Conductive heat transfer of the hot gas in the $z$-and $x$-directions is negligible.

With the above-mentioned assumptions, heat balances produce the following equations. Regarding the hot gas in the heat-recovering section,

$$
\begin{aligned}
& \rho_{h} u_{h} c_{h} \frac{\partial T_{h}}{\partial x}+a_{s} h_{h s}\left(T_{h}-T_{s}\right) \\
& +a_{h w} U_{h w}\left(T_{h}-T_{a}\right)=0
\end{aligned}
$$

Regarding the granular bed in the heat-recovering section,

$$
\begin{aligned}
& k_{s \mathrm{II}} \frac{\partial^{2} T_{s}}{\partial z^{2}}+k_{s \mathrm{II}} \frac{\partial^{2} T_{s}}{\partial x^{2}}-\rho_{s} \epsilon_{s} u_{s} c_{s} \frac{\partial T_{s}}{\partial z}+q_{s} \\
& -a_{s w} U_{s w}\left(T_{h}-T_{a}\right)=0
\end{aligned}
$$

Though $q_{s}$ in Eq. (2) is equivalent to the second term of Eq. (1), they are written in different ways because of independent numerical calculations of $T_{s}$ and $T_{h}$, as described later. For the granular bed in the heat-exchanging section including heat pipes,

$$
\begin{aligned}
& k_{s \mathrm{I}} \frac{\partial^{2} T_{s}}{\partial z^{2}}-\rho_{s} \epsilon_{s} u_{s} c_{s} \frac{\partial T_{s}}{\partial z}-a_{s H P} h_{s H P}\left(T_{s}-T_{H P}\right) \\
& -a_{s w} U_{s w}\left(T_{s}-T_{a}\right)=0
\end{aligned}
$$

For the heat pipe elements,

$$
\begin{aligned}
& a_{s H P} V_{s} h_{s H P}\left(T_{s}-T_{H P}\right) \\
& -a_{c H P} V_{c} h_{c H P}\left(T_{H P}-T_{c}\right)=0
\end{aligned}
$$

For the cold gas in the heat-exchanging section including heat pipes,

$$
\begin{aligned}
& k_{c} \frac{\partial^{2} T_{c}}{\partial z^{2}}+\rho_{c} u_{c} c_{c} \frac{\partial T_{c}}{\partial z}+a_{c H P} h_{c H P}\left(T_{H P}-T_{c}\right) \\
& -a_{c w} U_{c w}\left(T_{c}-T_{a}\right)=0
\end{aligned}
$$

\footnotetext{
it The temperature difference at both ends of the heat pipes of the experimental apparatus for the simulation can be estimated to be $1.5^{\circ} \mathrm{C}$ from the transferred heat of about 174.5 W per each heat pipe and the total thermal resistance of about $10^{-2}{ }^{\circ} \mathrm{C} / \mathrm{W}$. The difference in temperature at the both ends of the heat pipes with small thermal resistance can be neglected, since the temperature difference between the heat pipes and the granular bed as well as that between the heat pipes and the cold gas are in the range of 10 to $15^{\circ} \mathrm{C}$.
}

The boundary conditions are set to be as follows:

At the inlet of particles: $T_{s}=T_{s i}, \frac{\partial T_{s}}{\partial z}=0$

At the inlet of the hot gas: $T_{h}=T_{h i}$

At the inlet of the cold gas: $T_{c}=T_{c i}$

\section{2 Estimation of heat transfer coefficient}

The following equations were applied to estimate heat transfer coefficients for the simulation.

(a) Heat transfer coefficient between the hot gas and the granular bed

In order to estimate this, the following equation for the heat transfer coefficient between the particles and the fluid flowing through the fixed-bed was used ${ }^{2)}$ :

$$
\frac{h_{h s} d_{p}}{k_{h}}=2.0+1.8 P_{r}^{1 / 3} R_{e p}^{1 / 2}\left(P_{r} R_{e p}>10^{2}\right)
$$

Additionally, the measured values shown in Kunii's "Thermal Unit Operation (I)" were expressed by the following equation:

$$
\frac{h_{h s} d_{p}}{k_{h}}=10^{\left\{1.33 \log \left(P_{r} R_{e p}\right)-1.67\right\}}\left(P_{r} R_{e p} \leq 10^{2}\right)
$$

where

$$
R_{e p}=\frac{\rho_{h} u_{o} d_{p}}{\mu_{h}}
$$

(b) Effective thermal conductivity of the granular bed

For the calculation of effective thermal conductivity of the fixed bed with fluid flow, the term caused by conduction in the solid phase $k_{s \text { II }}$ and the ones in the fluid phase $k_{h x}, k_{h z}$ which denote effective thermal conductivity in the parallel and vertical direction to the flow respectively, were considered separately applying the following equation:

$$
\frac{k_{s \mathrm{II}}}{k_{h}}=\frac{k_{s \mathrm{I}}}{k_{h}}-\epsilon
$$

The effective thermal conductivity of the fixed bed without fluid flow $k_{s I}$ was calculated by the following equation ${ }^{2)}$ :

$$
\frac{k_{s I}}{k_{h}}=\epsilon\left(1+\beta \frac{h_{r v} d_{p}}{k_{h}}\right)
$$




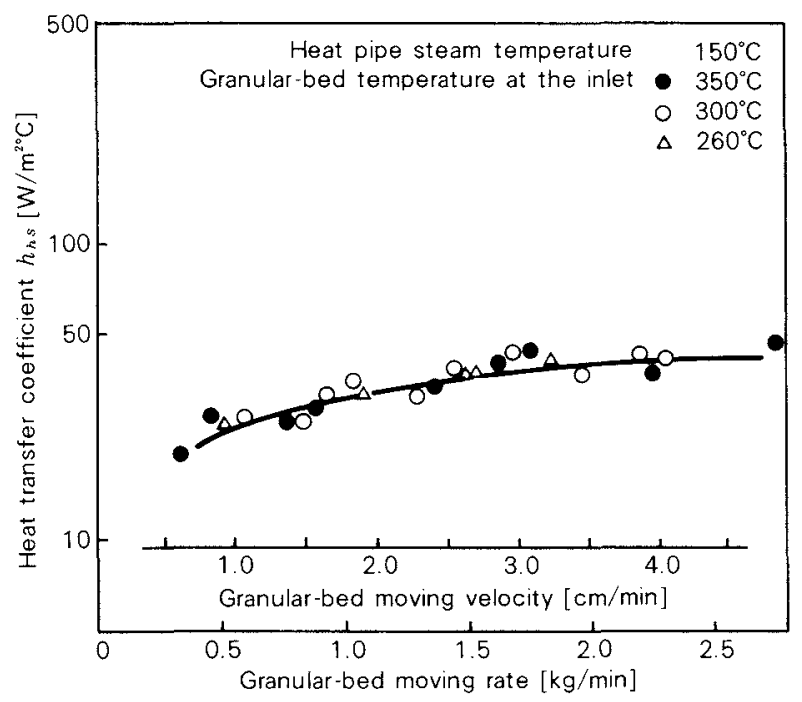

Fig. 3 Variation of the heat transfer coefficient between silica sands and heat pipes with the moving rate of silica sand granular bed

$$
+\frac{1-\epsilon}{\frac{1}{\phi}+\frac{d_{p}}{k_{h}}\left(h_{r s}+h^{*}\right)}+\gamma\left(\frac{k_{h}}{k_{s}}\right)
$$

The heat transfer by conduction of the hot gas to be determined with $k_{h x}, k_{h z}$,

$$
\begin{aligned}
& k_{h x}=c_{h} \rho_{h} D_{h} \\
& k_{h z}=k_{h}(\alpha \beta) P_{r} R_{e p}+\epsilon k_{h}
\end{aligned}
$$

was neglected according to the assumption $(g)$.

(c) Heat transfer coefficient between the granular bed and the heat pipes

This coefficient was obtained from the experiments described in the Appendix, the results of which, shown in Fig. 3, were used for the simulation.

(d) Heat transfer coefficient between the heat pipes and the cold gas

The heat transfer coefficient in the case where fluid flows vertically to the pipes with fins was calculated by the following equation ${ }^{3)}$.

$$
\begin{aligned}
& \frac{h_{c H P} D_{e}}{k_{c}}=0.251\left(\frac{D_{e} G_{\max }}{\mu_{c}}\right)^{0.67}\left(\frac{S_{1}-D_{r}}{D_{r}}\right)^{-0.2} \\
& \times\left(\frac{S_{1}-D_{r}}{Y}+1\right)^{-0.2}\left(\frac{S_{1}-D_{r}}{S_{2}-D_{r}}\right)^{0.4} \\
& D_{e}=\frac{A_{r} D_{r}+A_{r} \sqrt{A_{f} /\left(2 n_{f}\right)}}{A_{r}+A_{f}}
\end{aligned}
$$

\section{Numerical analysis method}

The fundamental equations concerning the heat transfer in a moving granular-bed have been solved differently in a large number of reports since the research by Amundson ${ }^{4)}$. Lately, as a result of the remarkable spread of computers, numerical analysis has come to be a principal method and has made the consideration of complicated shapes and detailed boundary conditions possible. As the heat exchanger concerned in our present work has heat-recovering and heat-exchanging parts which have different mechanisms of heat transfer, we have developed original procedures and methods for numerical calculation based on the finite difference method corresponding to each mechanism.

\section{1 Division into infinitesimal elements and difference equations ${ }^{5}$ )}

As mentioned above for modeling, there are two types of sections where the heat transferring mechanisms should be handled in oneor two-dimensions. Therefore, they were divided into the infinitesimal elements as shown in Fig. 2. The thermal difference equations are obtained as follows for individually numbered elements.

For the two-dimensional element $i$,

$$
\begin{aligned}
& \left(\frac{\partial T}{\partial z}\right)_{i}=\frac{T(i+m)-T(i-m)}{2 \Delta z} \\
& \left(\frac{\partial T}{\partial x}\right)_{i}=\frac{T(i+1)-T(i-1)}{2 \Delta x} \\
& \left(\frac{\partial^{2} T}{\partial z^{2}}\right)_{i}=\frac{T(i+m)-2 T(i)+T(i-m)}{(\Delta z)^{2}} \\
& \left(\frac{\partial^{2} T}{\partial x^{2}}\right)_{i}=\frac{T(i+1)-2 T(i)+T(i-1)}{(\Delta x)^{2}}
\end{aligned}
$$

For the one-dimensional element $o$,

$$
\begin{aligned}
& \left(\frac{\partial T}{\partial z}\right)_{o}=\frac{T(o+1)-T(o-1)}{2 \Delta z} \\
& \left(\frac{\partial^{2} T}{\partial z^{2}}\right)_{o}=\frac{T(o+1)-2 T(o)+T(o-1)}{(\Delta z)^{2}}
\end{aligned}
$$

When it comes to the elements on the boundary, forward and backward difference equations are applied. 


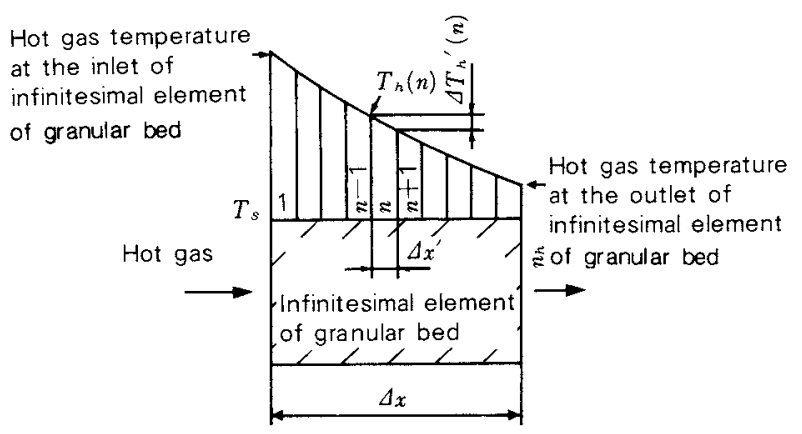

Fig. 4 Temperature distribution of the hot gas within an infinitesimal element of the granular bed

\section{2 Difference equations for the two-dimen- sional heat-recovering section}

(a) Determination of hot gas temperature

Near the inlet of the particles and the hot gas into the heat-recovering section, the temperature gradient of the hot gas in the $x$ direction is extremely steep. Therefore, the hot gas temperature was obtained by solving Eq. (1), for each infinitesimal element of the granular bed independent of the temperature of the granular bed. Namely, regarding $T_{s}$ to be constant in each element of the granular bed assigned in Fig. 2, Eq. (1) was modified to the following equation by dividing the elements into smaller subelements as shown in Fig. 4.

$$
\begin{aligned}
\Delta T_{h}^{\prime}(n)= & -\frac{1}{\rho_{h} u_{h} c_{h}}\left\{a_{s} h_{h s}\left(T_{h}(n)-T_{s}\right)\right. \\
& \left.+a_{h w} U_{h w}\left(T_{h}(n)-T_{a}\right)\right\} \Delta x^{\prime}
\end{aligned}
$$

$\Delta x^{\prime}$ and $\Delta T_{h}^{\prime}(n)$ denote a length of subdivision in the $x$-direction within the infinitesimal element of granular bed and the temperature change of the hot gas in the $n$-th subdivision.

The amount of heat transferred from the hot gas to the infinitesimal element of the granular bed per unit volume is calculated by numerical integration of the following equation:

$$
q_{s} \Delta x=-\sum_{n=1}^{n h} \rho_{h} u_{h} c_{h} \Delta T_{h}^{\prime}(n)
$$

(b) Determination of granular-bed temperature

Substituting the difference equation (16) for Eq. (2), the following difference equations are obtained for each infinitesimal element.

$$
\begin{aligned}
& E_{s, i} T_{s}(i-m)+A_{s, i} T_{s}(i-1)+B_{s, i} T_{s}(i) \\
& +C_{s, i} T_{s}(i+1)+F_{s, i} T_{s}(i+m)=G_{s, i}
\end{aligned}
$$

where $E_{s, i}, A_{s, i}, B_{s, i}, C_{s, i}, F_{s, i}, G_{s, i}$ are the coefficients or the constants consisting of the operational variables like velocity and of the characteristic properties such as heat transfer coefficient, specific heat and so on. The heatbalance equations concerning the infinitesimal elements of the granular bed which do not come into contact with the hot gas become difference equations of fundamentally the same from as Eq. (18), since the term of $q_{s}$ drops in Eq. (1).

\section{3 Difference equations in the heat-exchang- ing section of heat pipes}

(a) Determination of granular-bed temperature

Substituting the difference equation (17) for Eq. (3), difference equations for each infinitesimal element are obtained as below.

For the element $o$,

$$
A_{o, s} T_{s}(o-1)+B_{s, o} T_{s}(o)+C_{s, o} T_{s}(o+1)=G_{s, o}
$$

The heat-balance equation for the infinitesimal element of the granular bed which does not exchange heat with heat pipes comes to be the difference equation having basically the same form as Eq. (21) with the term $a_{s H P} h_{s H P}\left(T_{s}-\right.$ $T_{H P}$ ) being removed in Eq. (3).

At the junction part of one- and two-dimensional sections, the average temperature of the two-dimensional infinitesimal elements, which, for example, are in contact with element $l-1$, is used as the temperature of the infinitesimal element which is in contact with element $l-1$ in the $z$-direction.

$$
\begin{aligned}
& A_{s, l-1} T_{s}(l-2)+B_{s, l-1} T_{s}(l-1)+C_{s, l-1} \\
& \times\left\{T_{s}(l)+T_{s}(l+1)+\cdots+T_{s}(l+m-1)\right\} / m \\
& =G_{s, l-1}
\end{aligned}
$$

A similar procedure is undertaken for the element $l+k+1$.

(b) Determination of heat pipe temperature

The reformation of Eq. (4) gives the following equation for the element $p$.

$$
\begin{aligned}
& T_{H P}(p)=\frac{1}{a_{s H P} V_{s} h_{s H P}+a_{c H P} V_{c} h_{c H P}} \\
& \times\left(a_{s H P} V_{s} h_{s H P} T_{s}(o)+a_{c H P} V_{c} h_{c H P} T_{c}(r)\right)
\end{aligned}
$$




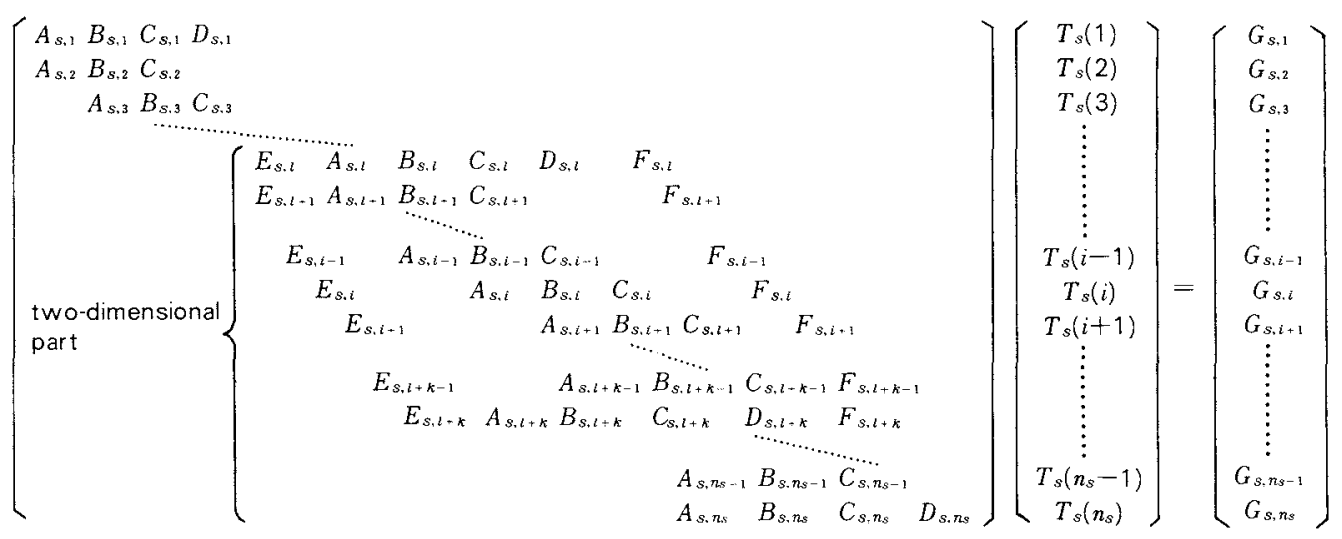

(a) For the granular-bed elements

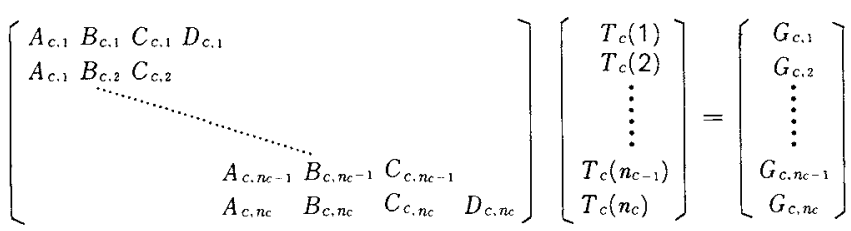

(b) For the cold gas elements

Fig. 5 Equation systems for the temperature of infinitesimal elements

Using the above equation, the temperature of the heat pipe element can be obtained from temperatures of infinitesimal elements of the granular bed containing the heat pipe element and those of the cold gas.

\section{(c) Determination of cold gas temperature}

Substituting difference equation (17) for Eq. (5), difference equations for each infinitesimal element are obtained as below.

For the element $r$,

$$
A_{c, r} T_{c}(r-1)+B_{c, r} T_{c}(r)+C_{c, r} T_{c}(r+1)=G_{c, r}
$$

The equation of heat balance regarding infinitesimal elements of the cold gas which do not exchange heat with the heat pipes is equivalent to Eq. (5) with the term $a_{c H P} h_{c H P}\left(T_{H P}-\right.$ $T_{c}$ ) being removed, and comes to have basically the same form as Eq. (24).

Using the above-mentioned difference equations, the temperatures of each part of the moving granular-bed type heat exchanger can be obtained for various operational conditions by repetition of the calculation.

The procedure for the calculation is as follows. First, the hot gas temperature and the amount of heat exchanged between the hot gas and the granular bed are obtained from Eqs. (18) and (19) with the assumed temperatures of the granular bed. Then the temperature of the granular bed is calculated from the equation system for the temperature of all the infinitesimal elements of the granular bed consisting of Eqs. (20), (21), etc. with the amount of exchanged heat (ref. to Fig. 5(a)). On the other hand, the cold gas temperature is calculated from the equation system for the temperature of all the infinitesimal elements of the cold gas consisting of Eq. (24) etc. (ref. to Fig. 5(b)). Furthermore, making use of the temperatures of the granular bed and the cold gas obtained in this way, the heat pipe temperature is obtainable from Eq. (23). The calculation is to be continued until the temperatures of each part converge. The whole calculation flow for the simulation is shown in Fig. 6.

\section{Experimental apparatus}

For the research and development of the moving granular-bed type heat exchanger, an experimental apparatus as shown in Fig. 7 was constructed. The hot gas treated with this type of heat exchanger usually contains a large amount of dust, the collection of which by the particles is one of the advantages of this type in addition to the recovery of the sensible heat of the gas. In the present work, however, the dust-free gas was used for an experiment concentrating on investigation of the thermal char- 


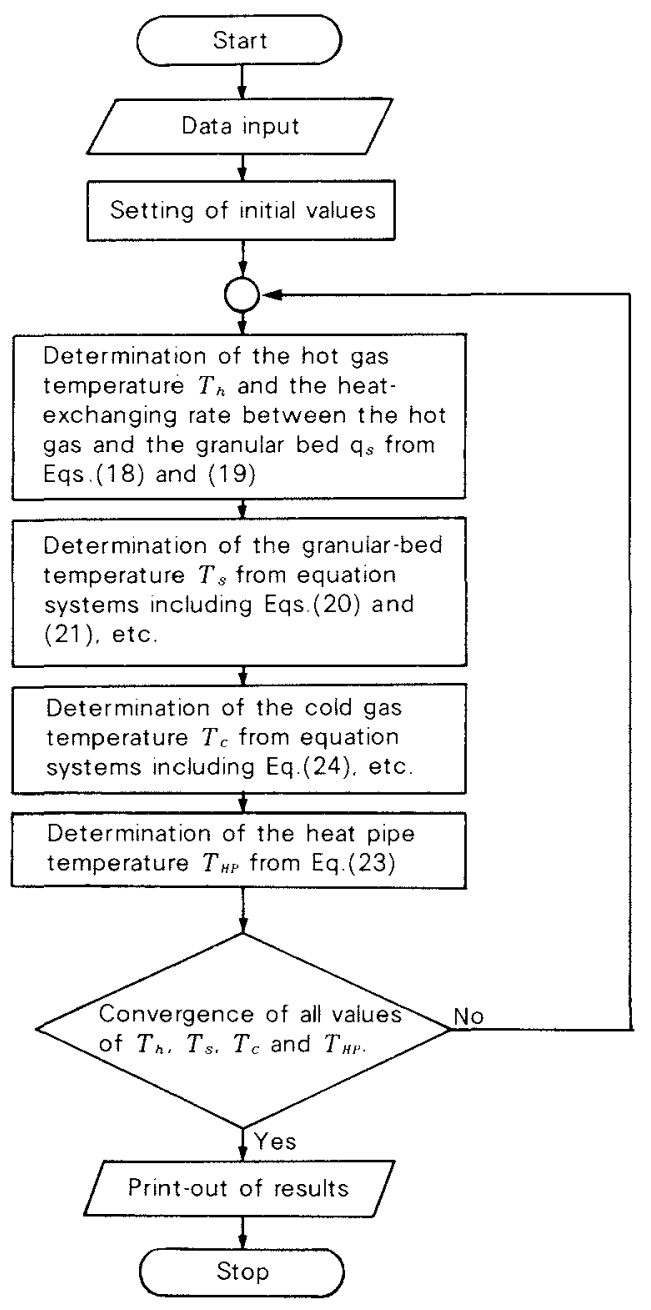

Fig. 6 Flow chart of calculation procedures

acteristics. In this experimental apparatus, silica sands having an average diameter of 1.75 $\mathrm{mm}$ and the air were used as the particles and the hot and the cold gas respectively. The heat pipes were made of clad pipes with inner and outer surfaces of copper and steel respectively operated with water as a heat carrier. The heatrecovering section of the experimental apparatus measured $1340 \mathrm{~mm}$ by $500 \mathrm{~mm}$ by $200 \mathrm{~mm}$ deep. The heat-exchanging section contained 6 units of heat pipes, one unit of which consisted of 14 pipes (in the arrangement of $4,3,4,3$ in a row) of $25.4 \mathrm{~mm}$ in outer diameter and 900 $\mathrm{mm}$ in length resulting in a total of 84 pipes. The maximal flow rates of the hot and the cold gas were $300 \mathrm{Nm}^{3} / \mathrm{h}$, and $400 \mathrm{Nm}^{3} / \mathrm{h}$ respectively. The moving rate of the granular bed was in the range from 150 to $350 \mathrm{~kg} / \mathrm{h}$.

The measurement of temperature was conducted with $C-A$ thermocouples at the following points:

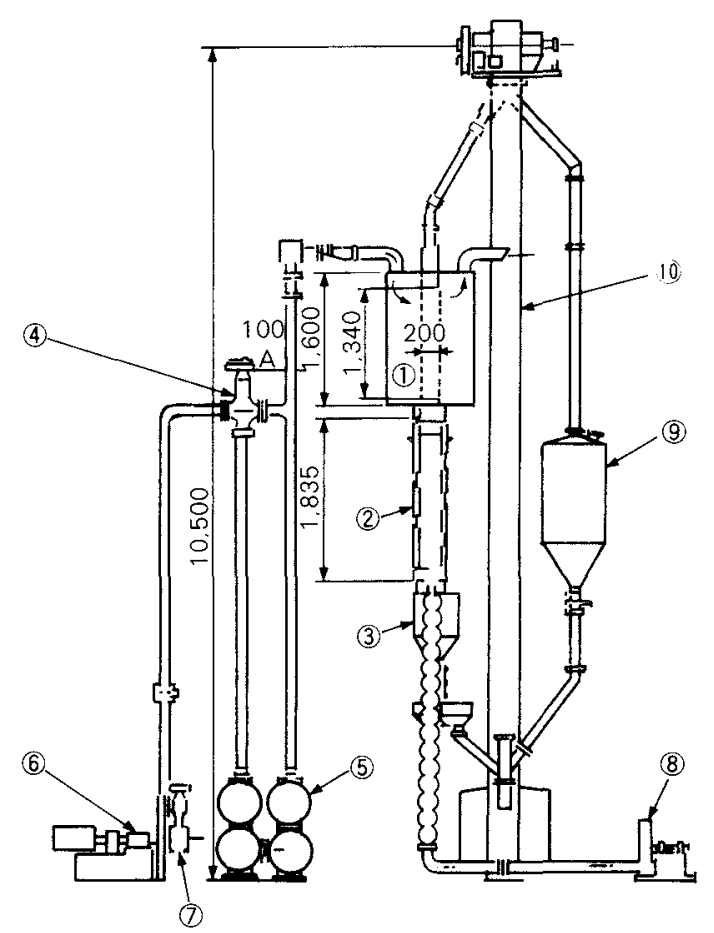

\footnotetext{
(1) Heat-recovering section

(2) Heat-exchanging section containing heat pipes

(3) Rotary feeder

(4) Three-way valve

5. Electrical heater

(6) Blower for the hot gas

(7) Flow control valve

(8) Blower for the cold gas

(9) Silo

(10) Bucket elevator
}

Fig. 7 Overall view of the experimental apparatus of a moving granular-bed type heat exchanger

For the hot gas

inlet

3 points

outlet

5 points

For the cold gas

inlet

1 point

in the middle

2 points

outlet

1 point

For silica sands

in the heat-recovering section 10 points

in the heat-exchanging section containing heat pipes

14 points

For steam inside the heat pipes 21 points

The mass flow rate of the hot gas was kept constant automatically with a data processor independent of frequent variation of the temperature through the measurement of the static pressure and the temperature at the measuring points as well as the pressure difference of the orifice flow meter. Additionally, the hot gas temperature at the inlet was made adjustable 


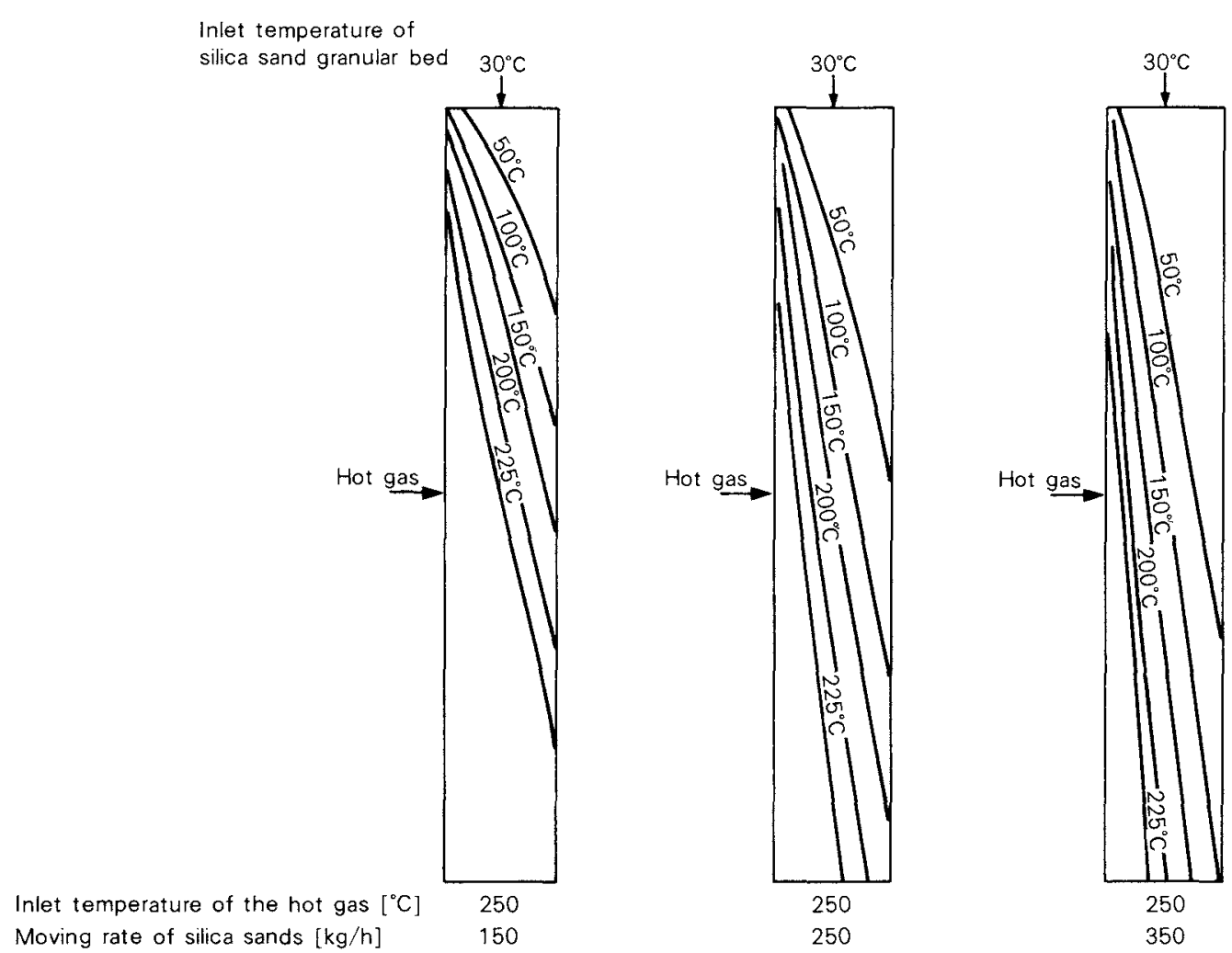

Fig. 8 Temperature distribution of silica sand granular bed within the heat-recovering section

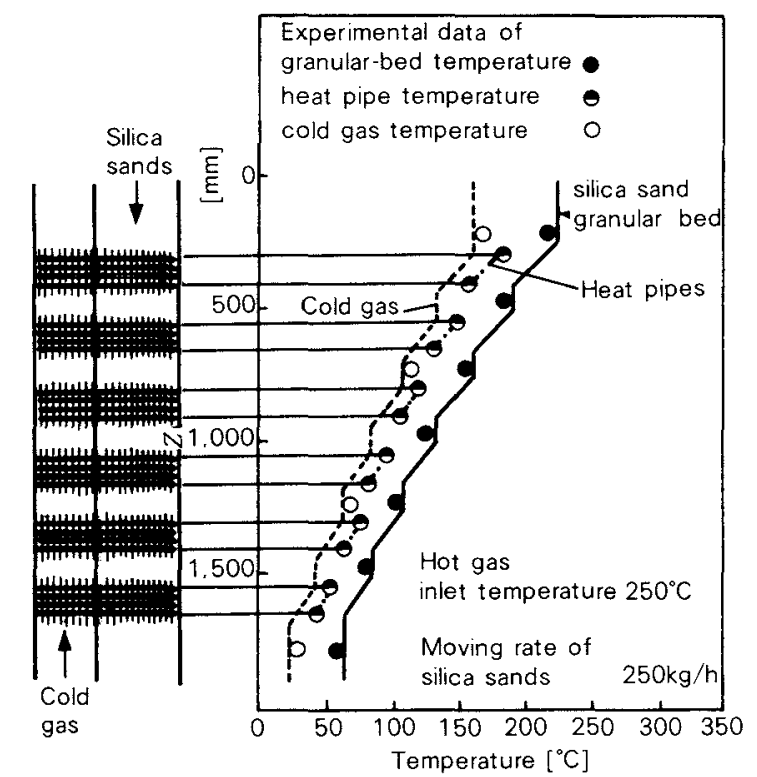

Fig. 9 Temperature distribution of the heat-exchanging section containing heat pipes

arbitrarily in the range from ambient temperature to $400^{\circ} \mathrm{C}$ by means of the control of the current to an electrical heater combined with a three-way valve. The flow rate of the cold gas was adjusted manually corresponding to the indication of an orifice flow meter.

\section{Comparison of the calculation results with the experimental ones}

The simulation was conducted according to the conditions of the experimental apparatus. It could give the temperature distribution of each part of the apparatus in a steady state under arbitrary operational conditions. For example, Fig. 8 shows the temperature distribution of silica sands in the heat-recovering section with a variation of their moving rate, keeping the inlet temperature and the flow rate of the hot gas constant. This figure gives information about the characteristics of the temperature rise of the silica sands in relation to their moving rate.

Figure 9 shows an example of the calculated temperature distribution of the silica sand bed, the heat pipes and the cold gas in the heatexchanging section containing the heat pipes together with plots of experimental results. The results obtained from calculation coincided well with the experimental ones quantitatively as well as qualitatively, which confirms the high accuracy of the calculation.

As an example to demonstrate the perform- 
Table 1 Comparison of the calculation results with the experimental ones

\begin{tabular}{|c|c|c|c|c|c|c|c|}
\hline & Item & & SE 1 & & ASE 2 & & ASE 3 \\
\hline \multirow{7}{*}{ Conditions } & Hot gas inlet temperature $\left({ }^{\circ} \mathrm{C}\right)$ & \multicolumn{2}{|c|}{250} & \multicolumn{2}{|r|}{350} & \multicolumn{2}{|r|}{250} \\
\hline & Hot gas flow rate $\left(\mathrm{Nm}^{3} / \mathrm{h}\right)$ & \multicolumn{2}{|c|}{200} & \multicolumn{2}{|r|}{200} & \multicolumn{2}{|r|}{200} \\
\hline & Silica sand inlet temperature $\left({ }^{\circ} \mathrm{C}\right)$ & \multicolumn{2}{|c|}{30} & \multicolumn{2}{|r|}{30} & \multicolumn{2}{|r|}{30} \\
\hline & Silica sand moving rate $(\mathrm{kg} / \mathrm{h})$ & \multicolumn{2}{|c|}{250} & \multicolumn{2}{|r|}{250} & \multicolumn{2}{|r|}{350} \\
\hline & Cold gas inlet temperature $\left({ }^{\circ} \mathrm{C}\right)$ & \multirow{2}{*}{\multicolumn{2}{|c|}{$\begin{array}{r}20 \\
200\end{array}$}} & \multirow{2}{*}{\multicolumn{2}{|c|}{$\begin{array}{r}20 \\
200\end{array}$}} & \multirow{2}{*}{\multicolumn{2}{|c|}{$\begin{array}{r}20 \\
200\end{array}$}} \\
\hline & Cold gas flow rate $\left(\mathrm{Nm}^{3} / \mathrm{h}\right)$ & & & & & & \\
\hline & & Calculated & Experimental & Calculated & Experimental & Calculated & Experimental \\
\hline \multirow{6}{*}{ Results } & Hot gas outlet temperature $\left({ }^{\circ} \mathrm{C}\right)$ & 76.8 & 80.7 & 99.1 & 95.2 & 48.3 & 57.2 \\
\hline & $\begin{array}{l}\text { Granular-bed temperature at the } \\
\text { outlet of heat-recovering section }\left({ }^{\circ} \mathrm{C}\right)\end{array}$ & 227.7 & 228.4 & 319.2 & 319.6 & 195.2 & 187.1 \\
\hline & Granular-bed outlet temperature $\left({ }^{\circ} \mathrm{C}\right)$ & 56.9 & 55.3 & 78.4 & 69.7 & 79.1 & 73.1 \\
\hline & Top heat pipe temperature $\left({ }^{\circ} \mathrm{C}\right)$ & 176.6 & 182.3 & 249.8 & 255.0 & 169.3 & 173.1 \\
\hline & Bottom heat pipe temperature $\left({ }^{\circ} \mathrm{C}\right)$ & 35.0 & 39.2 & 43.7 & 46.4 & 45.2 & 47.5 \\
\hline & Cold gas outlet temperature $\left({ }^{\circ} \mathrm{C}\right)$ & 158.9 & 166.5 & 226.7 & 232.2 & 158.9 & 164.4 \\
\hline
\end{tabular}

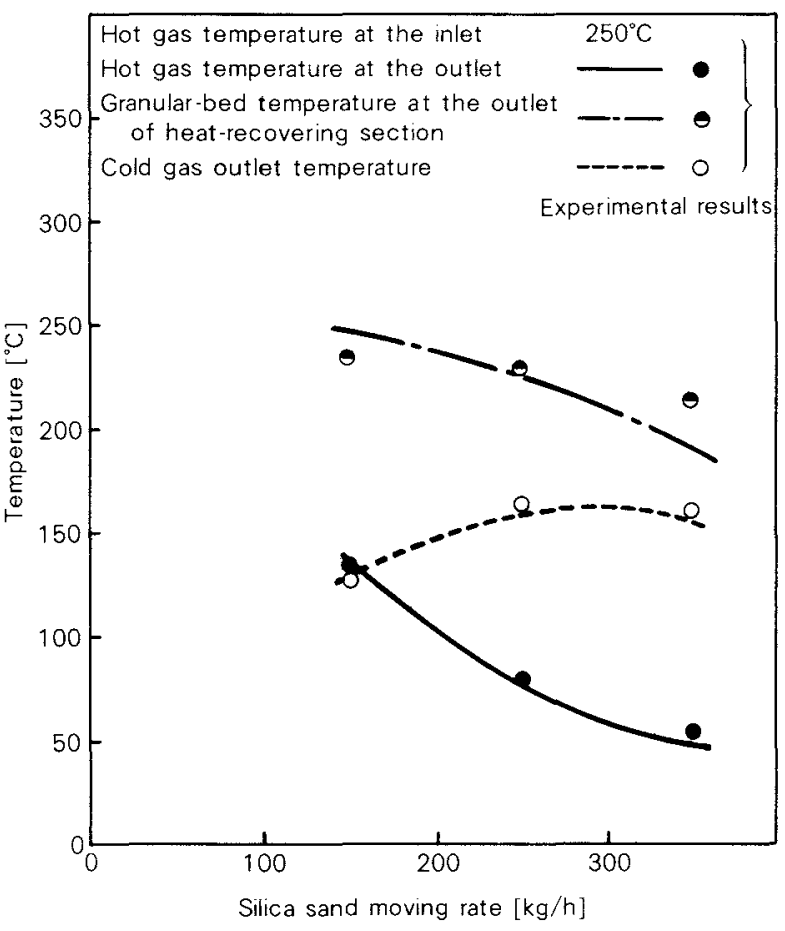

Fig.10 Variation of temperatures at some parts of the heat exchanger with the moving rate of silica sands

ance of the moving granular-bed type heat exchanger, theoretically obtained variations of the hot gas outlet temperature, the mean outlet temperature of the silica sand bed from the heat-recovering section and the outlet temperature of the cold gas with the moving rate of the silica sand bed are shown together with some experimental results in Fig. 10, with the other conditions constant. From this figure, it is seen that the results obtained from both calculation and experiments coincide well quantitatively as well as qualitatively. It is also possible to detect the optimal moving rate of the silica sands which gives the highest outlet temperature of the cold gas. For a quantitative comparison of the calculation results with the experimental ones, the values of each of the properties are shown in Table 1 in three cases of different operational conditions for the experimental apparatus. From the table it is affirmed that the theoretical and experimental results coincide well, allowing a difference of $8^{\circ} \mathrm{C}$ at most in each case. Furthermore, both results showed a consistency of similar degree under other operational conditions.

\section{Conclusion}

A simulation for the investigation of the thermal characteristics of the moving granularbed type of heat exchanger in the steady state was conducted solving difference equations using the numerical analysis method. In the simulation model, the calculation was performed two-dimensionally in the heat-rccovering section in contact with the hot gas and some adjacent parts of the granular bed where the temperature varied in the $z$-and $x$-directions, while the other parts were handled in one dimension.

The heat transfer coefficients between the hot gas and the granular bed and between the granular bed and the heat pipes were obtained from the general theoretical equations for packed beds with experimental data and from our experiments respectively. Furthermore, for the heat transfer coefficient between the heat pipes and the cold gas, we used an experimental equation which has been used to evaluate the heat transfer coefficient between pipes with fins and the fluid which flows vertically to 


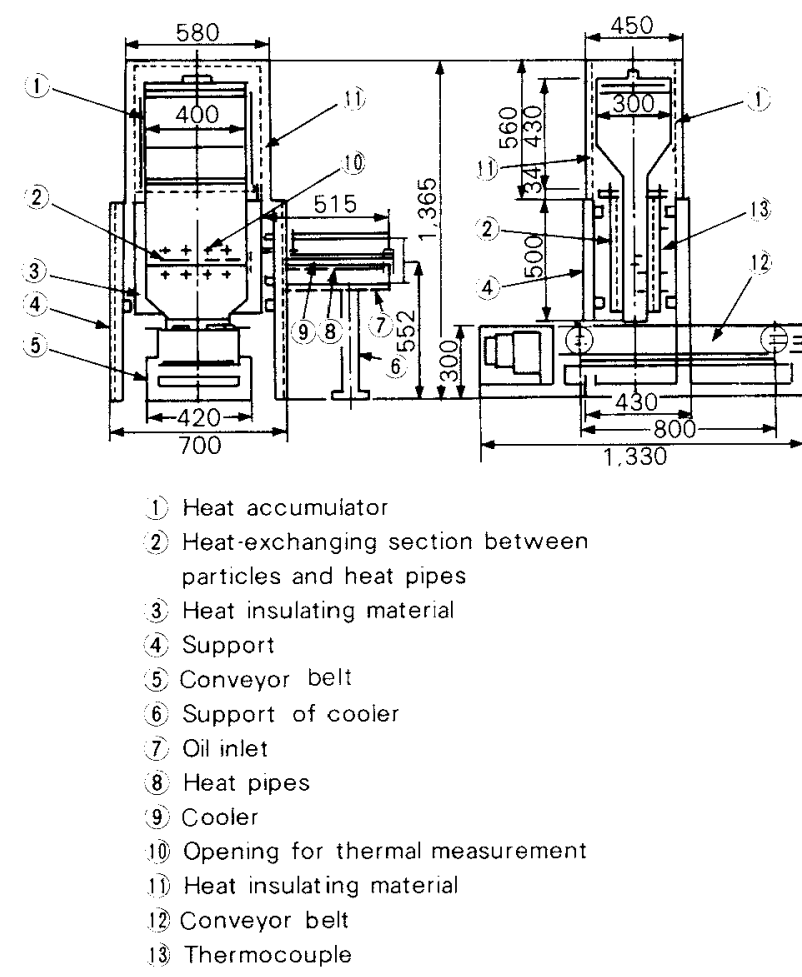

Fig. 11 Overall view of experiment apparatus of moving granular-bed type heat exchanging elements

rows of pipes.

The results from the simulation showed good agreement with those from the experiments, which confirmed that the thermal characteristics of the moving granular-bed type heat exchanger can be obtained with high accuracy by means of the method of the present research.

\section{Appendix}

\section{Measurement of heat transfer coefficient be- tween the granular bed and the heat pipes}

An experimental apparatus of heatexchanging elements of a moving granular bed shown in Fig. 11 was constructed for the purpose of measurement of the heat transfer coefficient between the granular bed and the heat pipes. This apparatus consisted of a heat-accumulating section at the top, the heat-exchanging section of heat pipes in the middle and the discharging device of particles of the moving bed at the bottom. The particles having a uniform temperature after being heated in an electrical oven for a long time were fed in the heat accumulator and were discharged from the bottom with a belt conveyor at a constant rate, so that they moved through the heat-exchanging sec- tion at a constant speed. The heat transfer coefficient between the granular bed and the heat pipes was obtained by measuring the temperature difference and the heat transferred between the granular bed and the outer surface of the heat pipes. Silica sands having a mean diameter of $1.75 \mathrm{~mm}$ were used as the particles. The experiments were conducted at three thermal settings of $350^{\circ} \mathrm{C}, 300^{\circ} \mathrm{C}$ and $260^{\circ} \mathrm{C}$ in the speed range of the moving granular bed in the heat-exchanging section from 0.5 to 5.0 $\mathrm{cm} / \mathrm{min}$. The results shown in Fig. 3 were made use of for the simulation.

\section{Nomenclature}

$$
\begin{aligned}
& A_{r} \text { : surface area per unit length of } \\
& \text { a heat pipe without fins } \quad\left[\mathrm{m}^{2} / \mathrm{m}\right] \\
& A_{f}: \text { surface area of fins per unit length } \\
& \text { of a heat pipe } \\
& a_{c H P} \text { : effective heat transferring area of }\left[\mathrm{m}^{2} / \mathrm{m}\right] \\
& \text { heat pipes with fins per unit } \\
& \text { volume on the side of cold gas } \quad\left[\mathrm{m}^{2} / \mathrm{m}^{3}\right] \\
& a_{c w} \text { : contact area of wall with cold gas } \\
& \text { per its unit volume } \\
& {\left[\mathrm{m}^{2} / \mathrm{m}^{3}\right]} \\
& a_{h w}: \text { contact area of wall with hot gas } \\
& \text { per its unit volume } \quad\left[\mathrm{m}^{2} / \mathrm{m}^{3}\right] \\
& a_{s}: \text { contact area of particles with hot gas } \\
& \text { per unit volume of granular bed }\left[\mathrm{m}^{2} / \mathrm{m}^{3}\right] \\
& a_{s H P} \text { : effective heat transferring area of } \\
& \text { heat pipes with fins per unit volume } \\
& \text { on the side of granular bed } \quad\left[\mathrm{m}^{2} / \mathrm{m}^{3}\right] \\
& a_{s w}: \text { contact area of granular bed with wall } \\
& \text { per unit volume } \quad\left[\mathrm{m}^{2} / \mathrm{m}^{3}\right] \\
& c_{c}: \text { specific heat of cold gas } \quad\left[\mathrm{J} / \mathrm{kg}^{\circ} \mathrm{C}\right] \\
& c_{h} \text { : specific heat of hot gas } \quad\left[\mathrm{J} / \mathrm{kg}^{\circ} \mathrm{C}\right] \\
& c_{s} \text { : specific heat of particles } \quad\left[\mathrm{J} / \mathrm{kg}^{\circ} \mathrm{C}\right] \\
& D_{h} \text { : mixing diffusivity of hot gas } \quad\left[\mathrm{m}^{2} / \mathrm{s}\right] \\
& D_{r} \text { : inner diameter of fins [m] } \\
& d_{p}: \text { particle diameter [m] } \\
& G_{\max } \text { : maximum mass velocity of fluid } \\
& \text { between heat pipes } \quad\left[\mathrm{kg} / \mathrm{m}^{2} \mathrm{~s}\right] \\
& h_{c H P} \text { : heat transfer coefficient between } \\
& \text { cold gas and heat pipes with fins } \quad\left[\mathrm{W} / \mathrm{m}^{2 \circ} \mathrm{C}\right]
\end{aligned}
$$




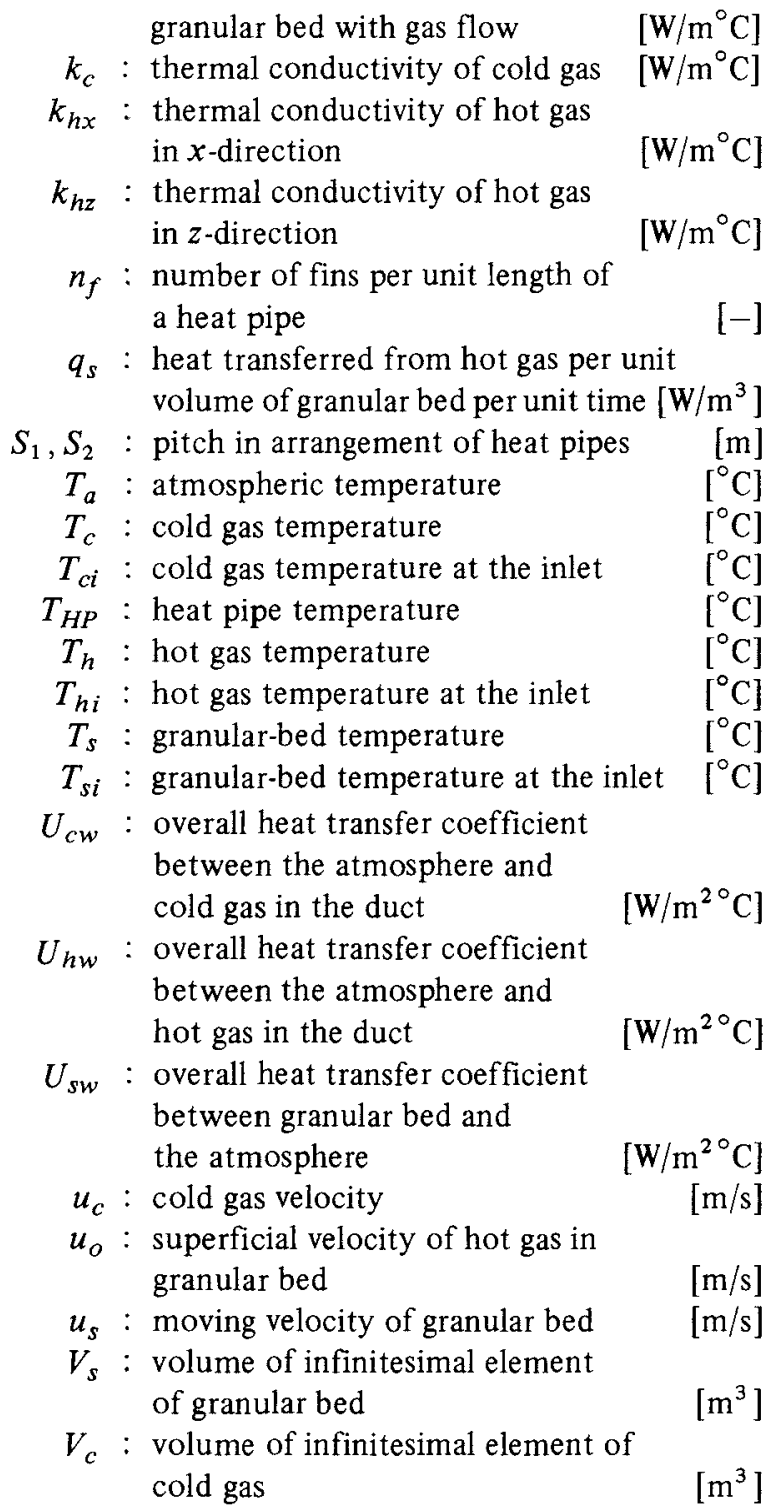

$\Delta x:$ length of infinitesimal element of granular bed in $x$-direction

$\Delta y$ : length of infinitesimal element of granular bed in $y$-direction

$\Delta z$ : length of infinitesimal element of granular bed in $z$-direction

$\alpha$ : a constant, equal to 0.179 at the closest packing

$\beta$ : ratio of mean distance between centers of two adjacent particles to particle diameter

$\gamma$ : ratio of mean thickness of granular bed to particle diameter

$\epsilon$ : void fraction

$\epsilon_{s}: 1-\epsilon$

$\mu_{h}:$ hot gas viscosity

$\rho_{c}:$ cold gas density

$\rho_{h}:$ hot gas density

$\rho_{s}:$ particle density

$\phi$ : ratio of effective thickness of fluid film in granular bed to particle size $\tau$ : time

\section{References}

1) The Japan Society of Mechanical Engineers: "Materials for Heat Transfer Engineering (The third edition)", 172 (1975).

2) Kunii, D.: "Thermal Unit Operation (I)", Maruzen Co., Ltd., 132-133 and 136-150 (1976).

3) Vampola, J.: Chem. Techn., 27, 26 (1965).

4) Amundson, N.R.: Ind. and Eng. Chem., 48, 26-50 (1965).

5) Togawa, H.: "Numerical Calculation of Differential Equations", Ohmsha Ltd. (1973). 